\title{
AC 2009-842: GREEN ISSUES IN A FACTORY: STUDENT PERCEPTIONS
}

\section{Lawrence Whitman, Wichita State University}

Lawrence E. Whitman is the Director of Engineering Education for the College of Engineering and an Associate Professor of Industrial \& Manufacturing Engineering at Wichita State University. He received B.S. and M.S. degrees from Oklahoma State University. His Ph.D. from The University of Texas at Arlington is in Industrial Engineering. He also has 10 years experience in the aerospace industry. His research interests are in enterprise engineering, engineering education and lean manufacturing.

\section{Janet Twomey, Wichita State University}

Janet Twomey is a Professor in the Industrial and Manufacturing Engineering Department at Wichita State University. She teaches graduate and undergraduate courses in modeling and simulation, neural networks, sustainability, and probability and statistics. Dr. Twomey's current research is in sustainable systems.

\section{Barbara Chaparro, Wichita State University}

Barbara S. Chaparro has a Ph.D. in Experimental Psychology from Texas Tech University and a B.S. in Psychology from University of Richmond, VA. She is an Assistant Professor in the Department of Psychology and director of the Software Usability Research Lab at Wichita State University. Her research interests include human-computer interaction, usability evaluation methods, and onscreen reading.

\section{Veronica Hinkle, Wichita State University}

Veronica D. Hinkle has an M.A. in Anthropology. She is currently working on her Ph.D. in Human Factors Psychology at Wichita State University. Her research interests include human-computer interaction, qualitative and quantitative methodology, and user-centered interface design. 


\title{
GREEN ISSUES IN A FACTORY: STUDENT PERCEPTIONS
}

\begin{abstract}
In order to meet the ABET requirements for sustainability, the environment must be considered. However, most students do not consider how decisions made when running a factory can impact the environment. Understanding these cause-and-effect relationships is key to evaluating and designing a production system. This paper presents a short overview of a simulation-based project useful for Production Systems/Operations Management courses. The simulation is flexible to cover basic course content as well as recent industry trends involving sustainability issues and the lean enterprise. It proves challenging for instructors to present these topics in a convincing manner to students, because many of these concepts, such as one-piece flow and reusable containers, are counterintuitive to traditional manufacturing logic. This paper presents the project itself, describes the application of modern production systems and the integration of environmental issues, and concludes with results from a (pre and post) survey of student perceptions of green issues in the factory and student ability to synthesize course concepts after the project is complete.
\end{abstract}

\section{Introduction and Motivation}

Students seldom consider environmental issues when applying course concepts. Students typically think that green issues are beyond the scope of their classes. Many students today want to do something to positively impact the environment, but believe that the only impact they can make is on a personal level. This is also true of industrial engineering students. They do not consider that how they act and the decisions they make can impact the environment. Introducing previously foreign concepts such as sustainability and environmental issues can be much more effective when complemented with a computer simulation. Simulation allows students to make decisions in dynamic real-world environments. The output from the simulation allows the student to evaluate the impacts of decisions and make necessary adjustments while learning new problem solving strategies. The manufacturing environment provides an excellent application of computer simulation. The complexity, uncertainty, and interdependencies of a factory are hard to convey from a textbook alone. Therefore, faculty use simulation to enhance their teaching effectiveness.

Studies show that the use of computer simulation can complement and improve traditional textbook methods. In addition to teaching concepts and theories presented in the textbooks, simulation can also stimulate group interaction and enable critical thinking, decision-making, and problem solving. A study by Gokhale ${ }^{1}$ shows that students remember only $10 \%$ of what they read and $20 \%$ of what they hear. However, students remember $90 \%$ of what they learn from simulation. The study goes on to suggest that properly designed and implemented computer simulations could revolutionize education. Results show that “...effective integration of computer simulation into traditional lecture-lab activities enhances the performance of the students"1. Student feedback from simulation projects indicates that they appreciate the relationship between real-world and course concepts, as well as the complexity of the decisionmaking process ${ }^{2}$. 
Students sometimes understand course concepts in a disconnected, isolated manner. Reciting theory and definitions are not of much use unless students can use that knowledge to make meaningful decisions. This project requires students to make business decisions based on uncertain and ambiguous information. Decision-making ability is a critical tool sought by employers. During the simulation, decisions occur simultaneously and interactively, rather than sequentially ${ }^{3}$. Allowing the student to practice decision-making in this environment is the primary objective of simulation. Traditional textbook and lecture methods normally have exercises designed around individual concepts. "This instructional method, while somewhat attributable to the usual trend to compartmentalize course material into homogeneous blocks, is more often due to an attempt to model traditional manufacturing organizations in which the product design function, manufacturing engineering, and production planning are separate corporate entities"4.

This paper reports on the use of simulation to enhance learning in a production systems course at Wichita State University. Production systems have become more complex due to technology as well as capital investment and the increase in the number and variety of products manufactured ${ }^{5}$. The factory is a complex system and most students have difficulty understanding its complexities. As Wichita is called, "The Air Capital," the factory simulated is an aircraft factory. The simulation presented here requires students to synthesize multiple class concepts in order to run an entire factory.

The current class project reinforces the fundamental concepts of forecasting, scheduling, Bill of Materials, capacity analysis, workforce analysis, holding costs and backorder costs. Students have commented that they have "really learned" the course content through the simulation. Through the existing project students develop a more thorough understanding of traditional production systems concepts. The existing class project uses a simple, non-trivial factory as shown in figure 1.

Many students are unaware of issues beyond typical classroom lectures. Sustainability and the environment are currently not taught as a separate course in the department offering production systems. The example used here is related to the idea of lean and green. One approach for lean and green manufacturing is for production systems to view pollution (and other elements of environmental impact such as production waste and energy consumption) as a quality "defect," then lean technologies will be pursued as "zero defect and zero emission" manufacturing strategies. In this sense, a lean and green relationship can transform the factory from traditional production to more innovative approaches such as environmentally conscious manufacturing which can improve the manufacturing process in ways that simultaneously improve environmental and industry performance, and reduce environmental cost and risks ${ }^{6,7,8}$. To do this students must be at least made aware of the relationship between lean and green. Toward this end, through an NSF funded project, we are extending the existing simulation based model to focus on the economic and environmental constraints and the broad education to understand the impact of engineering solutions in an economic, environmental and societal context.

In order to add environmental impacts to the simulation, during a class in the Fall 2008 semester students were asked about possible production decisions that could impact the environment. Students listed: packaging and material handling waste, excess energy use, water and cooling 
solvent usage and wastes, solid wastes, scrap and the use of hazardous materials and chemicals. Our selection of production related environmental impacts for inclusion in the simulation was based upon lean/green principles; that is - waste has adverse impacts on the environment. For the Fall 2008 semester, packaging material was incorporated. Early in the course of the simulation students are given the option to buy reusable containers used in shipping raw materials. The benefits of reusable containers are economic only; i.e. the environmental impacts are not quantified. The economic benefits arise from the trade-off between the onetime purchase of reusable containers versus the cost of packaging wastes for disposal.

\section{Project Design}

The primary impact of this project will be exemplary materials on how to incorporate lean and green concepts into student learning. Students in this class are given a quiz over several course concepts and asked their perceptions of several issues. The first quiz, administered in the early part of the semester, provided a baseline of existing student confidence that was used for comparison after the students completed the production systems course with the project.

The Bill of Materials had to be large enough to represent the different components of the aircraft, but was limited to about 30 part numbers in order to keep the magnitude of the production system simple enough for the students to handle. This Bill of Materials also includes raw material and purchased parts that must be ordered from a supplier. This requires the students to consider lead times when preparing production plans.

The Shockerphant production system is designed in order to incorporate the variability and complexity of a real production system. The system includes batch processing, one-piece-flow processing, resources shared by more than one workstation, purchased parts, make versus buy decision, scrap, rework, and scoring based on revenue and cost measures.

There are fourteen workstations in the Shockerphant production system and nine types of resources used at the different workstations. The system starts with two different types of raw material, aluminum sheets and other raw material; it then processes the raw material into other components of the aircraft. These components are then assembled in other workstations where they are combined with purchased goods as well as other manufactured assemblies. The first two levels of workstations are batch processes. Parts are processed and transferred according to the batch size indicated by the production order quantity. Parts in the other workstations are processed individually. Each workstation has a specific processing time for each part as well as a resource that is required to process the part. The correct material, resources and production order are required before processing can begin at the workstation. Initial parameters for processing times, lead times, scrap and rework rates were determined and the simulation was tested using those values. Figure 1 shows the existing factory flow. Raw materials begin the process through the first two operations. These processes occur in a batch environment and incur quality reject rates. The remaining processes are assembly operations that incur rework for any defective assemblies. The student teams determine the number of each resource (machines and workers), the batch size, order quantities, and whether to make or buy the interior. 


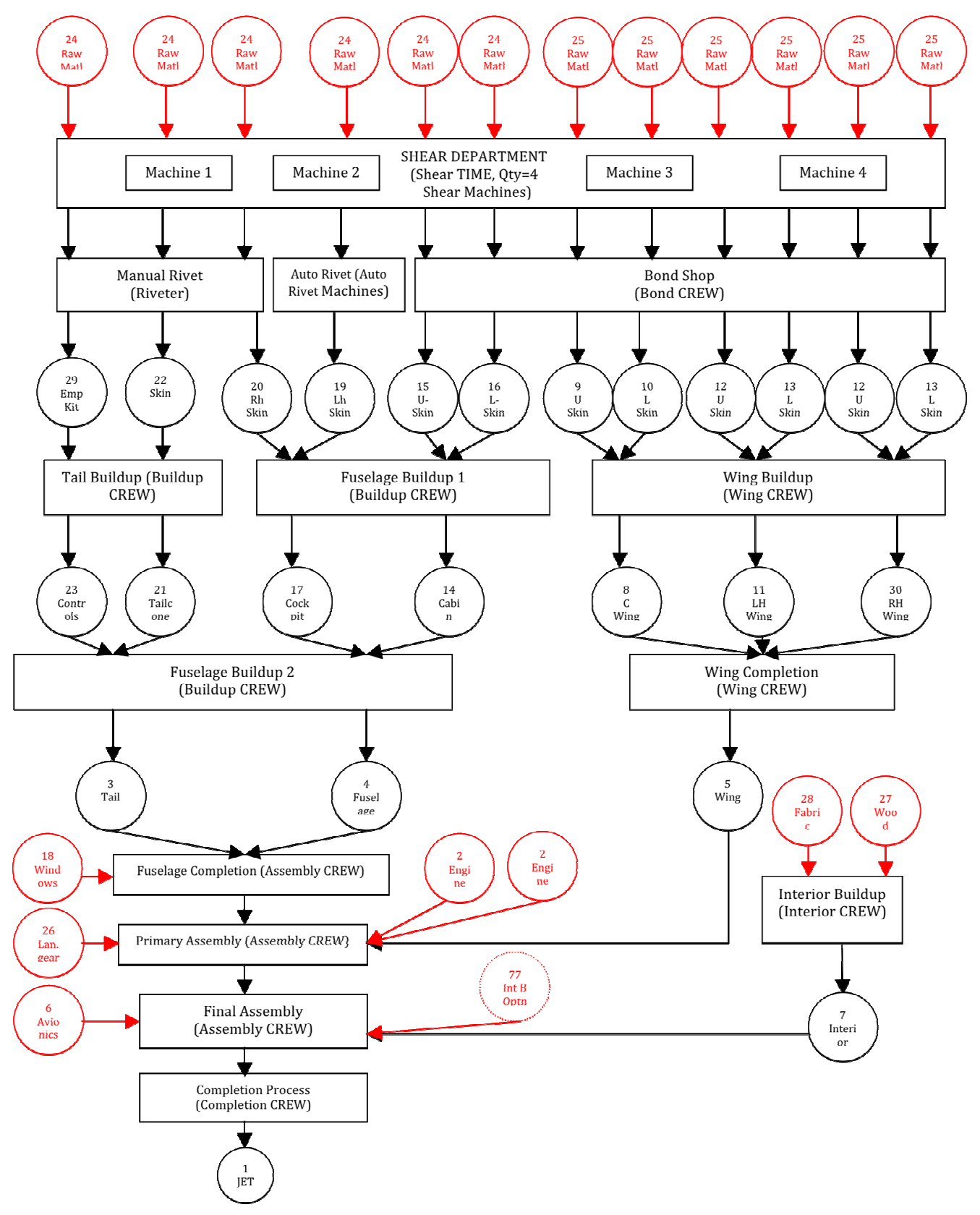

Figure 1. Shockerphant Factory Layout 
For more details concerning the Shockerphant factory and the project itself, please see the web site at: http://www.shockerphant.com/ which includes a user's manual, web lectures on its use, an assessment rubric, a virtual reality model file of the factory, a flash movie file describing the factory, the production sequence diagram, and the Bill of Materials. The simulation-based factory has been tested and improved and then used for eleven semesters at Wichita State University (Spring and Fall of 2002 through Fall 2008) with each class having four to nine teams of students.

\section{Survey/Quiz Analysis}

A widely held operational strategy that has been recognized to mitigate environmental impacts within the manufacturing enterprise is lean manufacturing principles ${ }^{10}$. Table 1 provides a list of what lean considers to be manufacturing 'wastes' with associated environmental impacts (adapted from [10]). For the modified project, the concepts in table 1 are being integrated into the project simulation model. The current goal is to introduce students to concepts of environmentally sustainable manufacturing through the application of lean concepts in a production setting. This project demonstrates to students that "lean and green" can be a cost effective strategy. As lean has been defined as "the relentless elimination of waste" "11, lean and green seem to naturally complement each other. The Environmental Protection Agency has funded several efforts in lean manufacturing hoping to leverage the environmental benefits of lean while creating greater economic benefits. Lean manufacturing essentially removes the waste from the system. Many of these production wastes also adversely affect the environment. In this project, waste reduction concepts (including environmental wastes) will be integrated into the project simulation model.

Table 1. The relationship between lean concepts and green production

\begin{tabular}{|c|c|c|}
\hline Wastes Type & Examples & Environmental Impacts \\
\hline Waiting & $\begin{array}{l}\text { Stock-out, lot processing } \\
\text { delays, equipment down } \\
\text { time, capacity bottle necks }\end{array}$ & $\begin{array}{l}\text { - Potential material spoilage or component } \\
\text { damage causing waste } \\
\text { Wasted energy from heating, cooling, and } \\
\text { lighting during production down time }\end{array}$ \\
\hline Inventory & Excess raw materials & $\begin{array}{ll}\text { - } & \text { More packing to store work in process } \\
\text { - } & \text { More material to replace damaged WIP } \\
\text { - } & \text { More energy to heat and light inventory } \\
\text { space }\end{array}$ \\
\hline Over production & $\begin{array}{l}\text { Excess raw materials, WIP, } \\
\text { or finished goods }\end{array}$ & $\begin{array}{l}\text { More raw materials used in making } \\
\text { unneeded goods } \\
\text { Extra products may spoil or become } \\
\text { obsolete }\end{array}$ \\
\hline Movement & $\begin{array}{l}\text { Human motions that are } \\
\text { unnecessary or straining, } \\
\text { carrying work in process, } \\
\text { long distances, transport }\end{array}$ & $\begin{array}{l}\text { - } \quad \text { More energy used for transport } \\
\text { - } \quad \text { Emissions from transport } \\
\text { increasing lighting heating, cooling and } \\
\text { light for inventory space }\end{array}$ \\
\hline
\end{tabular}

The primary research questions were to assess whether students more thoroughly understand production system concepts using a simulated factory project and whether they are able to think critically about parameters beyond class concepts (environmental impacts of production). A knowledge and attitude survey was developed to measure these two research questions at the 
beginning and end of the semester. This paper focuses on students' perceptions and attitudes of the impact of production decisions on the environment. At this point environmentally conscious manufacturing concepts are not brought into the classroom.

Integration of lean and green principles into the Shockerphant class project is the primary motivation for the modification of the project. The remainder of the paper describes the analysis of student responses for the three semesters in which data was collected.

A knowledge and attitude survey was created to measure the students' knowledge about production systems and their ability to apply concepts and theories to practical problems. The survey consisted of 15 knowledge questions representing Bloom's levels and 5 questions representing students' attitudes toward the perceived effectiveness of the class and materials used, as well as students' confidence of their abilities to apply key concepts to lean manufacturing. The questions for each Bloom's level were equivalent in difficulty and frame and were developed by an engineering professor. There were 4 application questions, 4 comprehension questions, 3 knowledge questions, 3 analyses, and 1 synthesis question. The component of the quiz/survey that is relevant to this paper is the question. The synthesis question asked of the student was: "If you were to manage (run) a factory, list the things you would do, in order. Think in terms of what you have learned (or will learn) in this class." There was one multiple choice question concerning perceived impact of production decisions on the environment and the student was then asked their confidence about their response to that question. This set of questions is shown in figure 2.

How easily/compatible are environmental (green) issues with production systems?

a. very compatible

b. compatible

c. not compatible

d. not at all compatible

What is the impact of waste in a production system on the environment?

How confident are you about answering the previous questions correctly?

a) I feel very confident I answered everything correctly

b) I feel somewhat confident that I answered some questions correctly

c) I am not sure how well I did in answering the questions

d) I do not feel confident I answered any of the questions correctly

Please tell us why you felt that level of confidence in answering the previous questions correctly.

Figure 2. Environmental questions from the student quiz/survey

Participants

This quiz and survey has been administered during three semesters. Forty-four students majoring in industrial engineering and enrolled in IME 553 for the Fall 2007 semester were asked to complete the knowledge and attitude survey regarding sustainability and production system 
concepts. Thirty-two students actually completed pre and post surveys. Twenty-six students in the Spring 2008 semester were asked to complete the quiz and survey. Twenty-five students actually completed pre and post surveys for this project. Thirty-four students in the Fall 2008 semester were asked to complete the knowledge and attitude survey regarding sustainability and production system concepts. Twenty-six undergraduate students actually completed pre and post surveys for this project.

\section{Procedure}

Students were administered a pre-test survey at the beginning of the semester and a post-test survey at the end of the semester by a graduate research assistant. At the beginning of the class period, students were informed that the survey was part of a student research project in order to remove any kind of performance anxiety while answering the questions. They were also told that the survey counted as a regular quiz toward their grade, so they were required to take the quiz. The students had approximately 20 minutes to complete the survey in each instance. Once all surveys were completed, results were scored by the same engineering professor who designed the questions.

\section{Results}

In the initial semester of using the survey, students did not all answer the survey questions as were told that it would not impact the grade. Due to this, the results from the Fall 2007 semester are not included. In the subsequent semesters, students understood that if they did not answer the survey questions, they would lose points from their quiz grade (but that there were no right or wrong answers). Table 2 shows the means and standard deviations, $t$ values, and significance (2tailed) for the pre and post surveys for the Spring and Fall of 2008 semesters.

Table 2. Means, std. deviations, t values, and significance (2-tailed) for the pre and post surveys.

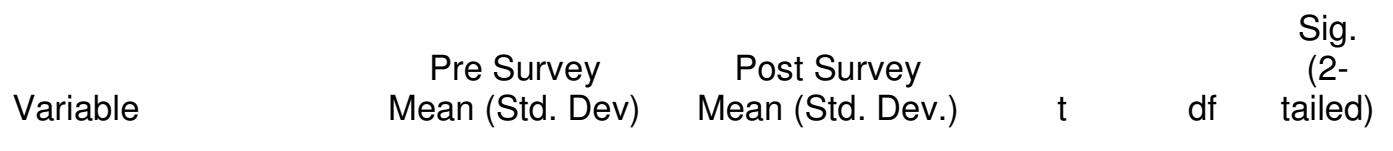

\section{Spring 2008}

Compatibility of environmental (green) issues with production systems Level of confidence on answering questions correctly

Fall 2008

Compatibility of environmental (green) issues with production systems

Level of confidence on answering questions correctly

$\begin{array}{lllll}2.65(0.78) & 2.63(0.82) & -0.44 & 21 & 0.67 \\ 3.08(0.65) & 3.13(0.69) & -0.24 & 21 & 0.81\end{array}$

$3.00(.63)$

$3.00(1.10)$

$0 \quad 25 \quad 1$

$\begin{array}{lllll}3.23(.86) & 2.92(1.06) & 1.32 & 25 & .20\end{array}$

\section{Discussion}

T-test results show that students' perception of the compatibility of environmental issues did not change after the project. In the Spring 2008 semester, no difference was expected as 
environmental issues were not explicitly addressed. In the Fall 2008 semester, a short class discussion ( $<10$ minutes) was held concerning what impacts were possible on the environment by production systems. From the discussion, the instructor led the students to decide to modify the project to include reusable containers. The choice of reusable containers was because it had already been implemented in the simulation model. However, as table 2 shows, there was still no significant difference in student attitudes in post-test.

\section{Conclusion and Future Directions}

This paper presented an overview of the existing simulation based virtual factory used by student to exercise the techniques they learn in production systems. While student perceptions of environmental issues has not shown a significant increase, this likely indicates that a single small external change to the project (reusable containers) is not significant enough to impact students' beliefs and attitudes. In the Spring 2009 semester additional environmental issues will be included. The simulation will be more impacted by the introduction of more and varied environmental factors and environmental impact metrics.

\section{Acknowledgments}

This material is based upon work supported by the National Science Foundation under Grant No. 0633014. Any opinions, findings, and conclusions or recommendations expressed in this material are those of the author(s) and do not necessarily reflect the views of the National Science Foundation. This work was also partially supported by the Department of Energy under Grant No. DOE DE-FG36-08GO88149.

\section{List of References}

1. Gokhale, A.A., Effectiveness of Computer Simulation for Enhancing Higher Order Thinking. Journal of Industrial Teacher Education, 1996. 33(4): p. 36-46.

2. Bringelson, L.S., et al., Training industrial engineers with an interfunctional computer simulation game. Computers \& industrial engineering, 1995. 29(1-4): p. 89 (4 pages).

3. Chapman, K.J. and C.L. Sorge, Can a Simulation Help Achieve Course Objectives? An Exploratory Study Investigating Differences Among Instructional Tools. Journal of education for business. 74, 1999(4).

4. Randhawa, S.U. and T.M. West, A Simulation-based Approach to Evaluating Design-Manufacturing Process. European journal of engineering education, 1994. 19(1): p. 31.

5. Khan, M.R., S. Harlock, and G. Leaf, Computer simulation of production systems for woven fabric manufacture. Computers \& Industrial Engineering, 1999: p. 37745-756.

6. Buxton, B. and E. Nielsen, How to be lean, mean and green. Financial Executive, 1995. 11(4): p. $29-33$.

7. King, A.A. and M.J. Lenox, Lean and green? An empirical examination of the relationship between lean production and environmental performance. Production and Operations Management, 2001.

8. $\quad$ Florida, R., Lean and Green: The Move To Environmentally Conscious Manufacturing. California Management Review, 1996. 39(1): p. 80-105.

9. Sutherland, J.W. and K.L. Gunter, eds. Environmental Attributes of Manufacturing Processes. Handbook of Environmentally Conscious Manufacturing, ed. C.N. Madu. 2001, Kluwer Academic Publishers,. 293316.

10. $\quad$ EPA. Lean Manufacturing \& the Environment: Opportunities for Environmental Improvement. 2003 [cited 2003 1/10/2008]; Available from: http://www.epa.gov/innovation/lean.htm.

11. Womack, J. and D. Jones, Lean Thinking, Banish Waste and Create Wealth in your Corporation. 1996, New York: Simon \& Schuster. 


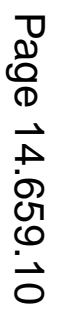

